\title{
The Future Development and Analysis of Vehicle Active Suspension System
}

\author{
Nouby M. Ghazaly, Ahmad O. Moaaz \\ Mechanical Engineering Dept., Faculty of Engineering, South Valley University, Qena-83523, Egypt. \\ Mechanical Engineering Dept., Faculty of Engineering, Beni-Suef University, Beni Suef-62511, Egypt.
}

\begin{abstract}
Ride comfort and the handling capabilities of vehicle are mainly determined by its suspension system, which transmits the forces between the vehicle and the road. In recent years, using active control mechanisms for design of active suspension system has attracted considerable attention. The main concept is use an active suspension to reduce the vibration energy of the vehicle body induced by the road excitation, while keeping the vehicle stability within an acceptable limit. The present paper aims at providing a picture - as complete as possible of the present state of the art in the active suspension control field in terms of ride comfort and road-holding performance evaluation. This paper discussed all the design literature review for active suspension systems for vehicle. This paper also deals with a number of control aspects and some of the important practical considerations.
\end{abstract}

Keywords: Active vehicle suspension; Fuzzy logic control; Preview control

\section{Introduction}

Suspension system is one of the critical components in the present of vehicle system. Ride safety and the handling capabilities of vehicle are mainly determined by its suspension system, which transmits the forces between the vehicle and the road. Suspension consists of the system of springs, shock absorbers and linkages that connects a vehicle to its wheels. In other meaning, suspension system is a mechanism that physically separates the car body from the car wheel. The main function of vehicle suspension system is to minimize the vertical acceleration transmitted to the passenger which directly provides road comfort. In the past few decades, many researchers have paid considerable attention to the issues on how to guarantee the stability of the suspension systems and how to improve the required suspension performances, namely, ride comfort, road handling and suspension deflection. So far, many vehicle suspension- system models have been proposed [1:4].

Generally, there are three types of system namely; passive, semi-active and active suspension system that have been widely investigated by many researchers with different techniques and algorithms. The passive suspension system showed lack of performance of vehicle stability as compared with semi-active and active suspension system. The dynamic behavior of passive automotive suspension systems is determined by the selection of the spring stiffness and the damper coefficient. The fixed damper and spring component of passive system has not well enough for energy absorption to sustain the load or road disturbance acted into the vehicle system [5:6]. The semi-active suspension system uses a variable damper or other variable dissipation component in the automotive suspension. An example of a variable dissipater is a twin tube viscous damper in which the damping coefficient can be varied by changing the diameter of the orifice in a piston [7:10]. Another example of semi-active dissipater is a magneto rheological (MR) damper which used MR fluid [11:14]. The MR fluids are materials that respond to an applied magnetic field with a change in rheological behavior. Typically, this change is manifested by the development of a yield stress that increases with applied magnetic field the dissipative force provided by the damper can be controlled by controlling the electromagnetic field. Semi-active suspension systems have been investigated in various literatures in order to achieve lower energy consumption and as good performance as full-active suspension systems [15:18]. The semi-active system can adjust the damping and thus improve either ride comfort or ride safety compared to the passive system. Active suspensions are equipped with electronic control systems that control the operation of the suspension elements. They have not a limited performance like passive suspensions and create a new advancement in removing the drawback of the design compromise present in passive suspensions. Active suspension systems reduce car body accelerations by allowing the suspension to 'absorb' wheel accelerations using an actuator [19:22].

Recently works and researches on active suspension have been carried out by many researchers in order to improve the stability and ride handling performance of the vehicle. So far, many control approaches such as Linear Quadratic Regulator (LQR) [23], Linear Quadratic Gaussian (LQG) control [24], Adaptive sliding control [25], Ho control [26], sliding mode control [27], fuzzy logic [28], preview control [29], optimal control [30] and neural network methods [31] have been used in the area of active suspensions. The performance of the active suspension system can be improved by control methods. However, these approaches 
need a complicated learning mechanism or a specific performance decision table and a certain difficulties in applications.

The present paper aims at providing a picture as complete as possible of the present state of the art in the active suspension control field in terms of ride comfort and handling. The paper will discuss all the design literature review for active suspension systems for vehicle. This review paper also deals with some of control strategies used for investigating active suspension.

\section{Development of Active Suspension Systems}

The basic idea in active control of suspensions is to use an active element (the actuator, e.g., a hydraulic cylinder) to apply a desired force between the vehicle and the wheel. Car's control unit computes the desired force to reach certain performance objectives under external disturbances (e.g., passenger comfort under road imperfections). The active suspension systems require several components such as ACs, servo valves, highpressure tanks for the control fluid, sensors for detecting the system, etc. [32]. Figure 1 describes basic component of active suspension. The associated power, which must be provided by the vehicle engine, may be very high depending on the required performance. Furthermore, these suspension systems are very expensive [33]. But, the full-active suspensions have better performance than passive suspensions.

Suspensions control is highly a difficult control problem due to the complicated relationship between its components and parameters. The researches were carried out in suspensions control systems cover a broad range of design issues and challenges. The control strategies of full-active suspension have been studied in many suspension systems to describe and improve the ride comfort and handling. For example, Hrovat [34] explored the connections between LQG-optimal one DOF (degrees of freedom) and two DOF models. The optimal two DOF systems indicated that both ride and handling can be improved by reducing the vehicle unsprung mass. Turkay and Akcay [35] used a quarter-car active suspension system by using the vertical acceleration and/or the suspension travel measurements for feedback. The influence of tire damping on the design of an active suspension system for a quarter-car model by a mixture of the LQG methodology and the interpolation approach was also illustrated. It was shown that tire damping by coupling the motions of the sprung and unsprung masses eliminates a constraint on the wheel-hop mode.

Recently, Aref Soliman 2011 [36] presented LQR control design for the control of a vehicle active suspension system. Seven DOF, full vehicle model was used. LQR control system was prepared as well as adaptive LQR control system (gain scheduling strategy) to study the effect of each control system using the active suspension on ride performance. The acceleration and dynamic tyre load were evaluated. For the time domain analysis, different road conditions were considered in order to reveal the performance of the two controllers. The simulation results showed that adaptive LQR control system gives a better ride performance compared with LQR control system.

In 2003, Abdelhady [37] presented a fuzzy scheme which offers new opportunities in the improvement of vehicle ride performance. The scheme handles uncertainties of the problem, and tunes the controller to treat the conflict requirements of ride comfort and road holding parameters within a specified amount of the suspension deflection. The two DOF quarter car model was used to evaluate the performance parameters when the vehicle was subjected to a random road input. Results of an active suspension system based on linear quadratic regulator (LQR) optimal control theory were also generated and used as a guide in scaling the performance of active systems with fuzzy control. It was indicated that the fuzzy logic control system improves both the ride comfort and road holding parameters in comparison with the LQR active suspension system.

Fateh and Alavi [38] developed an impedance control system to control dynamic behavior of a vehicle subject to road disturbances and applied the impedance control on an active vehicle suspension system operated by a hydraulic actuator. A quarter-car model of suspension system and a nonlinear model of hydraulic actuator were used to simulate the control system. The impedance control of active suspension system was performed well as it was preferred to passive suspension system. In comparison with model based control laws such as optimal control law, the IR showed important advantages.

Eski and Yildirim [39] designed neural network based robust control system to control vibration of vehicle's suspensions for full vehicle model. The proposed control system was consisted of a robust controller, a neural controller, a model neural network of vehicle's suspension system. Also they used the PID controller. Consequently, random road roughness was used as disturbance of control system. The performance of the neural network based robust control system is better than standard PID controller.

Demic et al. [40] introduced a design of active suspension systems using spatial vehicle model, without filtered feedback of the control system. A method of "stochastic parameters optimisation" has been utilized for the optimisation of the parameters of active suspension system. The optimisation objective was simultaneous minimization of sprung mass vibration and standard deviation of forces in tire-to-ground contact area and vehicle handling. The active suspension system has shown favorable characteristics in characteristic operating conditions, even without the filters in the feedback loops. A more sophisticated mathematical linear model for a 
roll-plane active hydraulically interconnected suspension (HIS) system was developed by Zhu et al. in 2014 [41]. For the verification of the new model, two simulations and corresponding experiments were conducted. Data comparisons between the simulations and experiments showed high consistent responses of the model and the real system, which validated the robustness and accuracy of the new mathematical model. In this process, the characteristics of the pressure response and the rise time inside the actuators have been revealed due to the presence of the flow.

Nguyen et al. [42] presented an active suspension system using $\mathrm{H} \infty$ control method for quarter car model with two DOF. Absolute velocity of car body was measured. The system parameter variations are treated with multiplicative uncertainty model. The simulation and experimental results showed that the Hoo controller can reduce considerably the gains from road disturbance to car body acceleration, to suspension deflection and to tire deflection at the frequencies around $1 \mathrm{~Hz}$.

In recent decades, fuzzy logic control has been suggested as an alternative approach to conventional control techniques for complex nonlinear systems. It was developed as a model-free control design approach, and it has been applied to active suspensions system to deal with the nonlinearities associated with the actuator dynamics, shock absorbers, suspension springs, etc. However, the model-free fuzzy logic control suffers from a number of criticisms, such as the lack of systematic stability analysis and controller design. It also faces a challenge in the development of fuzzy rules. Significant progress has been made in the past decades in the development of fuzzy logic control and it has been devoted to model based fuzzy control systems that guarantee not only stability, but also performance of closed-loop fuzzy control systems.

Yoshimura et al. [43] built an active EMS using the concept of sliding mode control. According to him, the sliding mode control was much better than LQ control concept and passive suspension system. Analytical solution was used to design the suspension system. As a result, the active suspension system using sliding mode control was much more better than active suspension that using LQ control concept and passive suspension system in terms of vibration isolation.

Attempts have been made by Lin et al. [44], in order to propose a fuzzy sliding mode controller (FSMC) to control an active suspension system and evaluated its control performance. The FSMC employed the error of the sprung mass position and the error change to establish a sliding surface, and then introduced the sliding surface and the change of the sliding surface as input variables of a traditional fuzzy controller (TFC) in controlling the suspension system. However, no substantial improvement in the ride comfort could be obtained with the FSMC relative to the TFC because the dynamic effect of the sprung mass acceleration from the bouncing tire during tire rotation was not eliminated. The EFSMC exhibits better control performance than either the TFC or the FSMC, in suppressing the acceleration of the vehicle body to improve the ride quality, and in reducing the tire deflection to increase the road-holding ability of a car, as confirmed by experimental results.

Yagiz et al. [45] studied, the active suspension control concept of a vehicle model that has five degrees of freedom with a passenger seat using a fuzzy logic controller. Three cases were considered as different control applications. In the first case, the vehicle model having passive suspensions with an active passenger seat was controlled. In the second case, active suspensions with passive passenger seat combination were controlled. In the third case, both the passenger seat and suspensions have active controllers. Vibrations of the passenger seat in the three cases due to road bump input are simulated. Among three control strategies considered, using controllers under the vehicle body and passenger seat at the same time would provide the best ride comfort. Since adding a controller under the passenger seat together with the active suspensions improves ride comfort the most and does not cost much, the third control application is to be preferred. liu et al. [46] proposed a quarter-automobile with active suspension system model. High speed on/off solenoid valves were used as control valves and fuzzy control was chosen as control method. Based on force analyses of system parts, a mathematical model of the active suspension system was established and simplified by linearization method. Experimental device was designed and produced. The active suspension system can achieve better vibration isolation performance than passive suspension system; the displacement amplitude of automobile body can be reduced to $55 \%$. Fuzzy control is an effective control algorithm method for active suspension system. Yoshimura and Takagi [47] presented the construction of a pneumatic active suspension system for a one-wheel car model using fuzzy reasoning and a disturbance observer. The active control was composed of fuzzy and disturbance controls, and the active control force is constructed by actuating a pneumatic actuator. A phase leadlag compensator was inserted to counter the performance degradation due to the delay of the pneumatic actuator. It was found that the proposed active suspension improves much the vibration suppression of the car model.

In order to achieve optimal vehicle performances and adaptability to the changes of plant parameters based on the defined objectives, a genetic algorithm is introduced to tune the parameters of PID controller, the scaling factors, gain values and the membership function of fuzzy logic controller on-line by Jinzhi et al. [48]. He proposed a new control strategy for active vehicle suspension systems using a combined control scheme, i.e., respectively using a genetic algorithm (GA) based self-tuning PID controller and a fuzzy logic controller in two loops. The PID controller was used to minimize vehicle body vertical acceleration and the fuzzy logic controller 
was to minimize pitch acceleration and meanwhile to attenuate vehicle body vertical acceleration further by tuning weighting factors. By a four DOF nonlinear vehicle model, the proposed control scheme was implemented and simulations were carried out in different road disturbance input conditions. The simulation results showed that the existing control scheme was very effective in reducing peak values of vehicle body accelerations, especially within the most sensitive frequency range of human response, and attenuating the excessive tire deflection to enhance road holding performance. It also showed a good stability and adaptability even if the system is subject to adverse road conditions, such as a pothole, an obstacle or a step input.

In 2007, Hany et al [49] considered Genetic Algorithm (GA) optimization technique to design an active suspension based on force cancellation concept when the vehicles crossing road humps. A longitudinal half vehicle model was used to represent passenger's car and truck models. These models were used to evaluate the performance of active suspension over the road speed humps. The force cancellation concept was employed to isolate the force between the sprung and unsprung mass. Virtual damper and skyhook damper concepts were also used for reducing the sprung mass acceleration and tire dynamic loads. GA was adopted to obtain the better coefficients of a virtual damper and a skyhook damper for its effective searching ability. The results were generated in time domain and represented as a root mean square values (RMS) and bar charts. It is shown both ride comfort and handling quality is greatly improved without exceeding the suspension stroke constraints.

Chiou et al. [50] designed a fuzzy logic controller (FLC) for an active automobile suspension system in which the membership functions and control rules were optimized using a genetic algorithm (GA). The objective of the FLC was to strike an optimal balance between the ride comfort and the vehicle stability. The values of the crossover and mutation parameters in the GA were adapted dynamically during the convergence procedure using a fuzzy control scheme. The GA-assisted FLC controller not only reduces the suspension deflection, sprung mass acceleration, and beating distance between the tire and the ground relative to that observed in a passive suspension system, but also provides a noticeably improved ride comfort and vehicle stability compared to that obtained when using a conventional optimal linear feedback control method.

$\mathrm{T}-\mathrm{S}$ (Takagi-Sugeno) fuzzy system is considered as one of the most popular systems in model-based fuzzy control. Since the T-S fuzzy model is very effective in presenting complex nonlinear systems, it is feasible to apply for handling the uncertainties of active suspension. There are many results on controller synthesis, stability analysis, and filter design for T-S fuzzy systems have been obtained [51-52]. For example, $\mathrm{H}$. Du and N. Zhang, [53] introduced a T-S model-based fuzzy control-design for electrohydraulic active suspension systems with input constraint. It was described by fuzzy IF-THEN rules that presented local linear input-output relations of a nonlinear system. The overall fuzzy model of the nonlinear system was found by fuzzy "blending" of the linear models. The T-S model is capable of approximating many real nonlinear systems, e.g., mechanical systems and chaotic systems. Since it utilizes linear models in the consequent part, linear control theory can be applied for system analysis and synthesis accordingly, based on the parallel-distributed compensation (PDC) scheme. Therefore, T-S fuzzy becomes powerful engineering tools for the modeling and control of complex dynamic systems.

One of the methods of active control of vehicle vibrations termed "preview control," involves measurement of road irregularities in front of the vehicle and utilizes this information to prepare the vehicle system for the oncoming input. While feedback control of vibrations has been extensively studied in the past, consideration of preview vibration control is relatively new. Preview active control of suspension involves the acquisition and use of information concerning the road profile ahead of the vehicle. Use of road preview information for improving vehicle suspension system was first proposed by Bender [54], as cited by Marzbanrad et al. [55]. Tomizuka [56] depicted the implementation aspect of the preview control of suspension in practice. The major tasks in the synthesis of preview control system for the actively controlled suspensions are (a) formulation of vehicle mathematical model; (ii) on-line synthesis of feed forward control policy to track the road elevation and partially counteract the forces imparted to the vehicle at the tire-road interface; and (iii) synthesis of an off-or on- line feedback control policy to augment the damping and suppress the vibrations caused by road irregularities.

In preview active control of suspension, there are two sets of variables that need to be sensed and used in the control scheme. Preview of road irregularity information is used as the feed forward component of the control strategy, while the state variables of the suspension system provide the basis for the feedback part of the control scheme. These variables need to be measured and be used in the implementation of the optimal control law. Arunachalam et al. [57] in their review paper described the road disturbances caused by the road followed by the need and history of preview system. Also, Oraby et al. 2007, [58] used a practical hydro-pneumatic limited bandwidth active suspension system with and without wheelbase preview control to study its influence on the vehicle stability in lateral direction. The model was a longitudinal half car with four degrees of freedom. Vehicle lateral dynamics was modeled as a two degrees bicycle model and a driver model. The controllable suspension system was designed based on linear optimal control theory using LQR control technique with front to rear axle preview is taken into account. The interaction between the performance of active suspension and 
vehicle lateral dynamics is studied through a non-linear Magic Formula tire model. The results were generated in the time domain to simulate the vehicle response in handling maneuvers while road wheels were subjected to vertical road input.

Further development has been made in 2014 by Mina Kaldas and Aref Soliman [59]. They investigate the influence of the preview control of the active suspension on the vehicle ride and braking performance. The vehicle performance was examined theoretically using a longitudinal half vehicle model with four degrees of freedom considering the rotational motion of the tires. The active suspension system model, tire-road interface model and braking system model are included in the vehicle model. Also, Akihito Yamamoto et al. in 2014 [60], examined the effect of a preview control using the eActive3 electric active suspension system, which is capable of controlling the roll, pitch, and warp modes of vehicle motion. They reported the results of a study into a preview control that uses the displacement of the road surface in front of the vehicle to improve for front and rear actuator responsiveness delays, as well as delays due to calculation, communication, and the like.

\section{Conclusions}

The following observations can be made from the previous survey:

1. For three different types of suspension systems, it has been extensively accepted that active suspension controller is more effective in improving suspension performance than the conventional passive and semi active suspension systems.

2. The performance of the neural network based robust control system is better than standard PID controller.

3. The fuzzy logic control system improves both the ride comfort and road holding parameters in comparison with the LQR active suspension system.

4. The T-S fuzzy models are becoming powerful engineering tools for the modeling and control of complex dynamic systems.

5. The GA-assisted FLC controller not only reduces the suspension deflection, sprung mass acceleration, and beating distance between the tire and the ground relative to that observed in a passive suspension system, but also provides a noticeably improved ride comfort and vehicle stability compared to that obtained when using a conventional optimal linear feedback control method.

6. The simulation results showed that adaptive LQR control system gives a better ride performance compared with LQR control system.

\section{References}

[1]. E. M., Elbeheiry, D. C., Karnopp, "Optimal Control of Vehicle Random Vibration with Constrained Suspension Deflection" Journal of Sound and Vibration, 189 (5): 1996, 547-564.

[2]. M. A. Aref Soliman, Nouby M. Ghazaly, Fatma S. Kadry "Parameters Affecting Truck Ride Comfort" SAE Technical Paper $2014-$ 01-0147, 2014, DOI:10.4271/2014-01-0147.

[3]. N. Al-Holou, T. Lahdhiri, D. Joo, J. Weaver, and F. Al-Abbas, "Sliding mode neural network inference fuzzy logic control for active suspension systems," IEEE Trans. Fuzzy Syst., vol. 10, no. 2, Apr. 2002. pp. 234-246.

[4]. Li Hongyi, Yu Jinyong, Chris Hilton, and Honghai Liu "Adaptive Sliding-Mode Control for Nonlinear Active Suspension Vehicle Systems Using T-S Fuzzy Approach” IEEE Transactions on Industrial Electronics, VOL. 60, NO. 8, AUGUST 2013.

[5]. R. Alkhatib, G. Jazar, Nakhaie, M.F. Golnaraghi, Optimal design of passive linear suspension using genetic algorithm, Journal of Sound and Vibration 275, 2004, 665-691.

[6]. S. Segla and S. Reich "Optimization and comparison of passive, active, and semi-active vehicle suspension systems" 12th IFToMM World Congress, Besançon (France), June18-21, 2007.

[7]. M. Valasek, M. Novak, Z. Sika, and O. Vaculin, "Extended Ground-Hook - New Concept of Semi-Active Control of Truck Suspension," Vehicle Syst. Dyn., vol. 29, 1997, pp. 289-303.

[8]. J. J. H. Paulides, E. Laurentiu, L. A. Elena, et al., "Design Considerations for A Semi-Active Electromagnetic Suspension System," IEEE Trans. On Magnetics, vol. 42, no. 10, Oct 2006.

[9]. S.-J. Heo, K. Park, S.-H. Son, Modelling of continuously variable damper for design of semi-active suspension systems, International Journal of Vehicle Design 31 (1), 2003, 41-57.

[10]. C. Spelta, "Design and Applications of Semi-Active Suspension Control Systems," Ph.D. dissertation, Politecnico de Milano, 2008.

[11]. A. Giua, M. Melas, C. Seatzu, Design of a control law for a semi-active suspension system using a solenoid valve damper, Proceedings of the 2004 IEEE Conference on Control Applications, Taipei, Taiwan, 2004.

[12]. S.W. Cho, H.J. Jung, and I.W. Lee, "Smart passive system based on a magnetorheological dampers", Smart Materials and Structures 1, 2005, 707-714.

[13]. E. Wang, X. Qing, S. Rakheja, and C. Su, "Semi-active Control of Vehicle Vibration with MR-dampers," in IEEE Conf. on Decision and Control, 2003, pp. 2270-2275.

[14]. G. Z. Yao, F. F. Yap, G. Chen, et al., "MR Damper and Its Application for Semi-Active Control Of Vehicle Suspension System," in Elsevier, vol. 12, March 2001, pp. 963-973.

[15]. H. Sohn, K. Hong, K. Hong, and Wan-Suk Yoo. "An adaptive LQG control for semi-active suspension systems" International Journal of Vehicle Design, Vol. 34, No. 4, 2004, pp. 309-326.

[16]. M. Yokoyama, J.K. Hedrick, S. Yoyama, A sliding mode controller for semi-active suspension systems, Transactions of the JSME 67-657 (C) (2001-2005) 1449-1454.

[17]. Do, A. L., Sename, O., Dugard, L., An LPV control approach for semi-active suspension control with actuator constraints. In: Proceedings of the IEEE American Control Conference (ACC). Baltimore, Maryland, USA, July 2010, pp. 4653 - 4658.

[18]. B. L. J. Gysen, J. J. H. Paulides, J. L. G. Janssen, et al., "Active Electromagnetic Suspension System For Improved Vehicle Dynamics,” IEEE Conf. on Vehicle Power and Propulsion, vol. 59, September 2008, pp. 1156-1163. 
[19]. B. L. J. Gysen, J. L. G. Janssen, J. J. H. Paulides, et al., "Design Aspects of an Active Electromagnetic Suspension System for Automotive Applications," IEEE Conf. on Industry Applications Society Annual Meeting, pp. 1-8, 5-9 Oct 2008.

[20]. Y. M. Sam and K. Hudha, "Modelling and Force Tracking Control of Hydraulic Actuator for an Active Suspension," 1st IEEE Conf. on Industrial Electronics and Applications, May 2006, pp. 1-6, 24-26.

[21]. J. Lich, "Optimal Design of Active Suspensions Using Damping Control," ASME of vibration and acoustics, vol. 119, Oct. 1997, pp 609-611.

[22]. T. Yoshimura, A. Kume, M. Kurimoto, et al., "Construction Of An Active Suspension System Of A Quarter Car Model Using The Concept Of Sliding Mode Control," Journal of Sound And Vibration, vol. 239, , January 2001, pp. 187-199.

[23]. M. S. Yahaya, and M. R. A. Ghani, "LQR Controller for Active Car Suspension,” Proc. On TENCON, Malaysia, 2000.

[24]. Ulsoy,A. G., D. Hrovat and T. Tseng(1994).Stability robustness of LQ and LQG active suspensions. ASA4EJ. Dynamic Systems, Measurement and Control, 116(1), 123-131.

[25]. PC Chen, Huang AC. Adaptive sliding control of non-autonomous active suspension systems with time-varying loadings. J Sound Vib 2005; 282(3-5):1119-35.

[26]. Du H, Zhang N. "Hळ control of active vehicle suspensions with actuator time delay. J Sound Vib 2007; 301(1-2):236-52.

[27]. Elnaz Akbari, Morteza Farsadi, Intan Z.Mat Darus ,Ramin Ghelichi “Observer Design for Active Suspension System U sing Sliding Mode Control "Proceedings of 2010 IEEE Student Conference on Research and Development, 13 - 14 Dec 2010 , Putrajaya, Malaysia.

[28]. H., Elbab, Allam, E., Hady, M., and Abouel-Seoud, S., "Performance of Active Suspension with Fuzzy Control," SAE Technical Paper 2009-01-1614, 2009.

[29]. W. A. H. Oraby, M. A. Aly, S.M. El-Demerdash, A. M. Selim “ Influence of Active Suspension Preview Control on the Vehicle Lateral Dynamics “ SAE 2007-01-2347.

[30]. E.M., El Beheiry, and D.C., Karnopp, "Optimal Control of Vehicle Random Vibration with Constrained Suspension Deflection," Journal of Sound and Vibration, Vol. 189, No. 5, Feb. 1996, pp. 547-564.

[31]. N. Al-Holou, T. Lahdhiri, D. Joo, J. Weaver, and F. Al-Abbas, "Sliding mode neural network inference fuzzy logic control for active suspension systems,” IEEE Trans. Fuzzy Syst., vol. 10, no. 2, Apr. 2002, pp. 234-246.

[32]. J. A., Allen "Design of active suspension control based upon use of tubular linear motor and quarter car model, Msc. Thesis, Texas A\&M University, August 2008.

[33]. B. Ebrahimi "Development of Hybrid Electromagnetic Dampers for Vehicle Suspension Systems" PhD thesis, University of Waterloo, Waterloo, Ontario, Canada, 2009.

[34]. D. Hrovat, "Optimal Active Suspension Structures for Quarter-car Vehicle Models" International Federation of automatic control, Vol. 26, No. 5, 1990, pp. 845-860.

[35]. T. Semiha and A. Huseyin."Aspects of achievable performance for quarter-car active suspensions" Journal of Sound and Vibration, Volume 311, Issues 1-2, Pages 440-460, 2008.

[36]. M. A. Aref Soliman "Adaptive LQR Control Strategy for Active Suspension System " SAE Technical Paper, 2011-01-0430.

[37]. M.B.A. Abdelhady “A Fuzzy Controller for Automotive Active Suspension Systems” SAE Technical Paper, 2003-01-1417.

[38]. F. Mohammad M. Alavi, Seyed Sina. "Impedance control of an active suspension system" Journal of Mechatronics, Vol. 19, Issues 1, 2009, pp. 134-140.

[39]. E., İkbal. Yıldırım. Şahin. "Vibration control of vehicle active suspension system using a new robust neural network control system" Journal of Simulation Modelling Practice and Theory, Vol. 17, Issue. 5, 2009, pp. 778-793.

[40]. M., Demic, "Idendification of Vibration Parameters for Motor vehicles" Vehicle System Dynamics, 27:68-88, 1997.

[41]. S., Zhu, Du, H., Zhang, N., and Wang, L., "Development of A New Model for Roll-Plane Active Hydraulically Interconnected Suspension," SAE Int. J. Passeng. Cars - Mech. Syst. 7(2):447-457, 2014, doi:10.4271/2014-01-0053.

[42]. Nguyen, Tan Ti en, Nguyen, Van Giap, Kim, Sang Bong."Control of Active Suspension System by Using Hळ Theory" Transaction on Control Automation, and Systems Engineering, Vol. 2, No. 1, pp. 1-6, 2000.

[43]. T. Yoshimura, K. Watanabe, Active suspension of a full car model using fuzzy reasoning based on single input rule modules with dynamic absorbers, International Journal of Vehicle Design 31 (1) (2003) 22-40.

[44]. Lin, Jeen, Lian, Ruey-Jing, Chung-Neng Huang, Wun-Tong Sie."Optimal Active Suspension Structures for Quarter-car Vehicle Models" Journal of Mechatronics, Vol. 19, No. 7, 2009, pp. 1178-1190.

[45]. Y. Nurkan, Sakman, L emir, Guclu, Rahmi "Different control applications on a vehicle using fuzzy logic control" Journal of Sadhana ,Vol. 33, No. 1, 2008, pp. 15-25.

[46]. L., Shao-jun, H., Zhong-hua, Chen. Yi-zhang "Automobile active suspension system with fuzzy control" Journal of Central South University of Technology, Vol. 11, No. 2, 2004, pp. 206-209.

[47]. T., Yoshimuram, and Takagi, Atsushi. "Pneumatic active suspension system for a one-wheel car model using fuzzy reasoning and a disturbance observer" Journal of Zhejiang University, Vol. 5, No. 9. pp. 1060-1068., 2004.

[48]. F., Jinzhi, Yu Fan, Li Jun “An Investigation to Controller Design for Active Vehicle Suspension by Using GA-Based PID and Fuzzy Logic" SAE Technical Paper, 2002-03-04.

[49]. S. H. Hany, Al Adl M. Rabeih, Samir M. El-Demerdash, Younes K. Younes “Active Suspension of Highway Truck Seat Using Genetic Algorithms " SAE Technical Paper, 2008-04-14.

[50]. J. -S. Chiou and M. -T. Liu. "Using fuzzy Logic controller and evolutionary Genetic algorithm for automotive Active suspension system" International Journal of Automotive Technology, Vol. 10, No.6, 2009, pp. 703-710.

[51]. B. Chen, X. Liu, S. Tong, and C. Lin, "Observer-based stabilization of T-S fuzzy systems with input delay," IEEE Trans. Fuzzy Syst., vol. 16, no. 3, pp. 652-663, Jun. 2008.

[52]. J. Qiu, G. Feng, and J. Yang, "A new design of delay-dependent robust Hœ filtering for discrete-time T-S fuzzy systems with time varying delay,” IEEE Trans. Fuzzy Syst., vol. 17, no. 5, Oct. 2009, pp. 1044-1058.

[53]. H. Du and N. Zhang, "Fuzzy control for nonlinear uncertain electrohydraulic active suspensions with input constraint," IEEE Trans. Fuzzy Syst., vol. 17, no. 2, Apr. 2009, pp. 343-356.

[54]. E.K. Bender, Optimum linear preview control with application to vehicle suspension. American Society of Mechanical Engineers, Journal of Basic Engineering 100 (1968) 213-221.

[55]. J. Marzbanrada, G. Ahmadib, H. Zohoorc, Y. Hojjatd "Stochastic optimal preview control of a vehicle suspension" Journal of Sound and Vibration 275, 2004, 973-990.

[56]. M. Tomizuka, "The Continuous Optimal Finite Preview Control Problem," Transactions of the Society of Instrument and Control Engineers, Vol. 12, No. 1, Feb. 1976, pp.7-12.

[57]. K. Arunachalam, P. Mannar Jawahar, P. Tamilporai “Active Suspension System with Preview Control - A Review" Technical Paper, 2003-28-0037. 
[58]. W. A. H. Oraby, M. A. Aly, S.M. El-Demerdash, A. M. Selim "Influence of Active Suspension Preview Control on the Vehicle Lateral Dynamics" SAE Technical Paper, 2007-01-234.

[59]. M.S. Mina Kaldas and M.A. Aref Soliman "Influence of Active Suspension Preview Control on Vehicle Ride and Braking Performance "SAE Technical Paper, 2014-01-0862.

[60]. A., Yamamoto, H., Sugai, Ryo Kanda, Shuuichi Buma "Preview Ride Comfort Control for Electric Active Suspension (eActive3)" SAE Technical Paper, 2014-01-0057. 